\title{
Stress-Hyperresponsive WKY Rats Demonstrate Depressed Dorsal Raphe Neuronal Excitability and Dysregulated CRF-Mediated Responses
}

\author{
Julia C Lemos', Guojun Zhang',3 ${ }^{1,3}$ Teresa Walsh', Lynn G Kirby' ${ }^{2}$ Adaure Akanwa', Amy Brooks-Kayal',3 \\ and Sheryl G Beck*, I
}

'Department of Anesthesiology, Children's Hospital of Philadelphia Research Institute and University of Pennsylvania, Philadelphia, PA, USA; ${ }^{2}$ Department of Anatomy and Cell Biology and Center for Substance Abuse Research, Temple University School of Medicine, Philadelphia, PA, USA; ${ }^{3}$ Division of Pediatric Neurology, Department of Pediatrics and Neurology, The Children's Hospital, University of Colorado School of Medicine, Aurora, CO, USA

\begin{abstract}
Major depression is a debilitating psychiatric disease that may be precipitated by a dysregulation of stress neurocircuitry caused by chronic or severe stress exposure. Moreover, hyperresponsivity to stressors correlates with depressed mood and may contribute to the etiology of major depression. The serotonergic dorsal raphe nucleus (DRN) is an important site in the neurocircuitry underlying behavioral responses to stressors, and is tightly regulated, in part, by a combination of intrinsic cell properties, autoinhibition, and GABAergic synaptic transmission. The stress-related neurotransmitter corticotropin-releasing factor (CRF) modulates DRN neuronal excitability and subsequent 5-HT release in the forebrain. Wistar Kyoto (WKY) rats exhibit exaggerated behavioral responses to stressors, that is, stress hyperresponsivity, and are considered an animal model of depression. To better understand the neurobiological basis of the stress hyperresponsivity, we used a combination of mRNA analysis and whole-cell electrophysiological techniques to measure differences in intrinsic activity and receptor response, in 5-HT- and non-5-HT-containing neurons of the DRN in WKY rats compared with SpragueDawley controls. In the WKY rat, there was a decrease in the neuronal excitability of 5-HT neurons coupled with decreased TPH2 production. Additionally, we found that CRF did not increase GABAergic activity in 5-HT neurons as is normally seen in 5-HT neurons of Sprague-Dawley controls. The CRF modulation of 5-HT DRN neurotransmission at the single-cell level is selectively disrupted in the WKY animal model of depression and may be one of the cellular correlates underlying depression.

Neuropsychopharmacology (20II) 36, 72I-734; doi: I0.1038/npp.20 I0.200; published online 15 December 2010
\end{abstract}

Keywords: dorsal raphe; WKY; stress hyperresponsive; corticotropin-releasing factor; GABA $A_{A}$ IPSC

\section{INTRODUCTION}

Major depressive disorder (MDD) is a debilitating psychiatric disease that is often co-morbid with anxiety and addiction. A leading theory of MDD is the monoamine depletion hypothesis that posits a causal link between lower monoamine tone and depressed mood (Ruhe et al, 2007). However, numerous preclinical and clinical studies have shown that either acute severe or chronic stress can precipitate the onset or relapse to psychiatric disorders, including depression, anxiety, and addiction (Drake et al, 2003; Schmidt et al, 2008; Walker et al, 2008). Therefore, a more accurate characterization of MDD may be a basal

*Correspondence: Dr SG Beck, Department of Anesthesiology, Children's Hospital of Philadelphia Research Institute, ARC, Room 402A, 3615 Civic Center Boulevard, Philadelphia, PA 19104, USA, Tel: + 2 I5 590 065I, Fax: + 2 I5 590 4I07, E-mail: becks@email.chop.edu Received 23 March 2010; revised 20 September 2010; accepted 12 October 2010 decrease in monoamine tone combined with dysregulated stress neurocircuitry.

The serotonergic dorsal and median raphe nuclei (DRN, MRN) are important sites in the neurocircuitry underlying behavioral responses to stressors (Adell et al, 1997; Dilts and Boadle-Biber, 1995; Leonard 2005; Maier and Watkins, 2005), and have been implicated in several stress-related pathologies including depression and anxiety (Deakin, 1991; Graeff et al, 1996; Kinney et al, 1997; Leonard, 2005; Maier and Watkins, 2005; Robinson et al, 1989; Stockmeier, 1997; Tao and Auerbach, 2002). Humans and rodents exhibiting depression-like symptoms demonstrate evidence of 5-HT dysfunction (Deakin, 1991; Stockmeier, 1997) that may be initiated by changes in the excitability of 5-HT neurons. The excitability of raphe neurons is mediated and modulated by intrinsic properties, norepinephrine input, fast inhibitory (GABA) and excitatory (glutamate) synaptic inputs, 5-HT1A receptor (5-HT1A)-mediated autoinhibition, and neuropeptidergic regulation (eg, orexin, opioid, and corticotropinreleasing factor (CRF)). 
Wistar Kyoto (WKY) rats exhibit exaggerated behavioral responses to stressors or stress hyperresponsivity; in tests of depression and anxiety, these animals show enhanced immobility in forced swim, reduced exploration in open field tests, hyponeophagia, and rapidly acquired learned helplessness when compared with Sprague-Dawley (SD) control rats (Lahmame et al, 1997; Pare, 1989b, 1994b; Pare and Redei, 1993a,b; Pare and Tejani-Butt, 1996; Will et al, 2003). In comparison with Wistar rats, WKY rats have prolonged elevation of corticosterone levels following acute stress (De La Garza and Mahoney, 2004). Dopamine, norepinephrine, and serotonin release, uptake, and modulation are altered in WKY rats. Specifically, when compared with SD rats, WKY rats show upregulation of both dopamine and norepinephrine transporter mRNA and protein expression, leading to a decrease in extrasynaptic catecholamine tone, a reduction in 5-HT levels in several brain regions (Scholl et al, 2010), and decreases in the efficacy of 5-HT antidepressants to alleviate symptoms of depression (Lopez-Rubalcava and Lucki, 2000; Tejani-Butt et al, 2003; Zafar et al, 1997) and anxiety (Pollier et al, 2000). Thus, WKY rats represent a useful animal model of stressrelated depression and anxiety; yet, changes in cellular characteristics, 5-HT1A receptor-mediated responses, excitatory and inhibitory synaptic inputs, and peptidergic effects in the DRN have not been investigated in these animals.

Based on evidence that serotonin levels are reduced in the forebrain of depressed individuals (Coppen and Doogan, 1988; Deakin, 1991; Grahame-Smith, 1989), we hypothesized that WKY rats would demonstrate changes in both intrinsic properties and modulation of synaptic currents, consistent with a depression in raphe 5-HT neuron excitability. These alterations may be because of up- or down-regulation of various G-protein-coupled receptor or ion channel expression levels in the cell or alterations in the function of these proteins at the cell surface. Therefore, we used a combination of mRNA analysis and in vitro electrophysiology to more accurately assess the mechanism(s) underlying various phenomenological cellular differences between SD and WKY rats.

A major hypothesis of our laboratory is that dysregulation of stress neurocircuitry is caused by desensitization of the receptor because of a chronic or prolonged elevation of the corresponding endogenous stress-related neurochemical. This phenomenon alters the response of the receptor system to acute stressors. Therefore, we predicted that CRF-mediated changes in 5-HT neuronal function would be abolished in 5-HT neurons of WKY rats because of an overactive stress system. This study extends the work done by our lab using electrophysiological techniques in a DRN and MRN in vitro slice preparation from SD rats to characterize intrinsic properties of 5-HT and non-5-HT neurons, 5-HT1A receptor-mediated responses (Beck et al, 2004), and CRF receptor-mediated responses (Kirby et al, 2008), by elucidating how these responses may be altered in the WKY animal model of depression.

\section{MATERIALS AND METHODS}

\section{Subjects}

Male SD and WKY rats (75-150 g) from Taconic Farms (Taconic, Germantown, NY) were housed two to three per cage on a 12-h light schedule (lights on at $0700 \mathrm{~h}$ ) in a temperature-controlled $\left(20^{\circ} \mathrm{C}\right)$ colony room. Rats were given access to standard rat chow and water ad libitum. All animals were used in accordance with the US Public Health Services Policy on Humane Care and Use of Laboratory Animals. All protocols were reviewed and approved by the IACUC committee. The majority of behavioral studies specifically examining the depression-like behaviors in the WKY rat have used SD rats as the control(s) (see Introduction). Therefore, $\mathrm{SD}$ rats were used as the control group for both the mRNA analysis and electrophysiology. As is standard for in vitro electrophysiology studies, slices from adolescent rats were used because of the high technical difficulty in maintaining healthy recordings from adult rats.

\section{Laser Capture Microdissection (LCM) and mRNA Analysis}

The rats were killed via decapitation, their brains removed, and frozen on dry ice. The brains were sectioned at $10 \mu \mathrm{m}$ intervals with a Leica CM3000 microtome/cryostat (Leica, Allendale, NJ) at $-20{ }^{\circ} \mathrm{C}$, and thaw-mounted onto microscope slides (Fisher Scientific, Waltham, MA). Subsequently, sections were stored in a $-80{ }^{\circ} \mathrm{C}$ freezer until they were processed for immunostaining. The sections were fixed with dithiobis(succinimidyl propionate) (DSP, $1 \mathrm{mg} / \mathrm{ml}$ ) for $5 \mathrm{~min}$, rinsed for $30 \mathrm{~s}$ in DEPC water, and incubated for $15 \mathrm{~min}$ in $1: 250$ dilution of antibody directed against TPH (Sigma, St Louis, MO). After a quick DEPC water rinse, they were placed in the DaKoCytomation antibody/enzyme complex for $20 \mathrm{~min}$, rinsed in DEPC water, and added to DaKoCytomation coloring solution for $5 \mathrm{~min}$ (the above solutions contained $200 \mathrm{U} / \mathrm{ml}$ RNasin). The slides were quickly dried at room temperature before the microdissections were performed. TPH-positive cells ( $\sim 1000$ cells) were dissected from 10 raphe sections from four animals per strain, using PALM MicroLaser system. The total RNA was isolated from the dissected cells using TRIzol reagent. The cDNA was synthesized using Superscript II Reverse Transcriptase with oligo dT-T7 primer. The double-stranded cDNA carrying a T7 RNA polymerase promotor was transcribed using the Ampliscribe transcription kit (Epicentre, Madison, WI). The aRNA was then again synthesized into a single-stranded cDNA template for a second round of amplification. The second round of aRNA was cleaned up using the RNeasy kit (Qiagen, Valencia, CA). Then, the $\mathrm{P}^{32}$-dCTP-labeled cDNA probe was synthesized using Superscript II. The probe was incubated at $95^{\circ} \mathrm{C}$ for $3 \mathrm{~min}$, purified and transferred to a prehybridized filter array, and incubated for $18 \mathrm{~h}$ in a hybridization chamber at $42{ }^{\circ} \mathrm{C}$. After the hybridization, filter arrays were washed four times with agitation in the following solutions: $2 \times \mathrm{SSC} / 1 \%$ SDS for $20 \mathrm{~min}, 0.5 \times \mathrm{SSC} / 1 \% \mathrm{SDS}$ for $20 \mathrm{~min}, 0.2 \times \mathrm{SSC} /$ $1 \%$ SDS, and $0.1 \times$ SSC/0.5\% SDS for $20 \mathrm{~min}$. Over 1000 5-HT-containing neurons throughout the rostral-caudal extent of the DRN were necessary to produce enough mRNA for analysis. The DRN is a heterogeneous brain region of which approximately one-third of the neurons in the DRN are non-5-HT containing. These non-5-HT neurons have various neurochemical identities and subfield locations. Therefore, it was not possible to use only one neurochemical marker for that population. Hence, only differences in 5-HT-containing neurons of SD and WKY rats were measured. 


\section{Slice Preparation}

Procedures were similar to those previously reported (Beck et al, 2004; Lemos et al, 2006). Animals were rapidly decapitated, head placed in ice-cold sucrose buffer, and the brain dissected and blocked. The blocked tissue was mounted on the stage of a Leica microslicer and surrounded in oxygenated sucrose buffer. Sections that were $200 \mu \mathrm{m}$ thick were cut through the raphe nuclei in sucrose and then placed in oxygenated $95 \% \mathrm{O}_{2} / 5 \% \mathrm{CO}_{2}$ ACSF with $50 \mu \mathrm{M}$ L-tryptophan (Sigma) and incubated in a $35-37^{\circ} \mathrm{C}$ bath for $1 \mathrm{~h}$. Addition of L-tryptophan is necessary to ensure 5-HT production ex vivo and helps prevent against false negatives during the post hoc immunohistochemical classification. The slices were then removed from the bath and kept in oxygenated ACSF at room temperature. ACSF was composed of (in mM): $\mathrm{NaCl} 124, \mathrm{KCl} 2.5, \mathrm{NaH}_{2} \mathrm{PO}_{4} 2, \mathrm{CaCl}_{2} 2.5$, Dextrose 10, and $\mathrm{NaHCO}_{3} 26$. The sucrose buffer was ACSF in which $\mathrm{NaCl}$ was substituted with $248 \mathrm{mM}$ sucrose.

\section{Electrophysiology}

Slices were placed in a recording chamber (Warner Instruments, Hamden, CT) and continuously perfused with oxygenated ACSF at $\sim 1.5 \mathrm{ml} / \mathrm{min}$, and maintained at $30-$ $32{ }^{\circ} \mathrm{C}$ by an inline solution heater (TC-324; Warner Instruments). Healthy recordings cannot be maintained for long periods of time if the ACSF is heated $>35^{\circ} \mathrm{C}$. For recording GABAergic synaptic activity, electrodes were filled with an intracellular solution (in $\mathrm{mM}$ ): 70 KGluconate, $70 \mathrm{KCl}, 2 \mathrm{NaCl}, 10$ Hepes, 4 EGTA, $4 \mathrm{Mg}$ ATP, $0.3 \mathrm{Na}_{2} \mathrm{GTP}$, and $0.1 \%$ biocytin at $7.3 \mathrm{pH}$ to yield a resistance of $4-8 \mathrm{M} \Omega$. To record cell characteristics, the electrolyte contained (in $\mathrm{mM}$ ): 140 KGluconate, $2 \mathrm{NaCl}, 10$ Hepes, 4 EGTA, $4 \mathrm{Mg}$ ATP, $0.3 \mathrm{Na}_{2}$ GTP, and $0.1 \%$ biocytin at a $7.3 \mathrm{pH}$ to yield a resistance of $6-10 \mathrm{M} \Omega$.

Whole-cell recordings, specifically to obtain cellular characteristics in current clamp and inhibitory postsynaptic currents (IPSCs) in voltage clamp, were performed on cells in the ventromedial aspect of the DRN. The cell was voltage clamped at $-70 \mathrm{mV}$ using an Axopatch 200B amplifier (Molecular Devices, Foster City, CA) or HEKA EPC-10 amplifier (HEKA Elecktronik, Pfalz, Germany). Signals were digitized by a Digidata 1320 A/D converter (Molecular Devices) and stored using pClamp 9 software (Molecular Devices). For the HEKA amplifier, signals were stored online using Pulse software (HEKA). Junction potentials between the electrode and the ACSF were $\sim 10-15 \mathrm{mV}$, as calculated using a program in Clampex, and were not subtracted out.

For voltage clamp experiments, once a whole-cell recording was established, $20 \mu \mathrm{M}$ DNQX and $1 \mu \mathrm{M}$ TTX were added to the ACSF to eliminate glutamatergic synaptic activity and action potential-dependent GABA release. Previously, we determined that there were no differences between spontaneous IPSCs and miniature IPSCs (mIPSCs), and hence TTX was added simultaneously with DNQX (Lemos et al, 2006). Traces of mIPSCs were recorded and stored online. A total of $10 \mathrm{nM}$ ovine CRF (oCRF; selective CRF receptor 1 (CRF R1) agonist) or Urocortin II (Ucn II, selective CRF R2 agonist) were added to the perfusion buffer and recording continued for 9-12 min. This concentration was chosen based on the reported affinities for specific receptors (Lovenberg et al, 1995). At the end of some of the protocols, bicuculline $(20 \mu \mathrm{M})$ was added to the bath to confirm that mIPSCs were mediated by $\mathrm{GABA}_{\mathrm{A}}$ receptors.

\section{Immunohistochemistry}

Standard immunohistochemistry procedures were used to assess the neurochemical identity of the recorded cell, as described in Beck et al (2004). Slices were incubated for at least $1 \mathrm{~h}$ in paraformaldehyde (4\%), and then placed in PBS, $0.5 \%$ Triton, and BSA for $30 \mathrm{~min}$. Slices were then incubated for $12-24 \mathrm{~h}$ in mouse anti-TPH primary antibody $(1: 500)$ (Sigma). Slices were subsequently incubated in donkey anti-mouse Alexa 488 secondary antibody $(1: 200$; Molecular Probes, Eugene, OR). Biocytin was visualized using streptavidin-conjugated Alexa 633 (1:200; Molecular Probes). Slices were imaged using a confocal microscope. Recorded cells were identified via the biocytin labeling. If a cell co-labeled with the TPH immunoreactivity, the cell was identified as 5-HT containing. Cells were confirmed as non5 -HT containing only if TPH immunoreactivity was seen in the same plane as the biocytin-filled cell. For $\mathrm{GABA}_{\mathrm{A}} \beta 3$ immunohistochemistry, $20 \mu \mathrm{m}$ cryosections were made through the rostrocaudal axis of the raphe from perfusion-fixed SD and WKY rat brains. Tissue was thaw mounted onto Superfrost slides and immunohistochemistry was carried out on the tissue, co-staining for TPH $(1: 500)$ and $\mathrm{GABA}_{\mathrm{A}} \beta 3$ protein $(1: 500)$ (courtesy of Stephen J Moss, $\mathrm{PhD}$, Tufts University). Tissue from SD and WKY rats were stained in parallel and images captured using the same exposure time and gain controls.

\section{Data Analysis and Statistics}

Current clamp experiments were analyzed using Clampfit 9.2 software. mIPSCs were analyzed using MiniAnalysis 6.0.3 (Synaptosoft, Dacatur, GA). Initially, noise analysis was conducted for each cell and amplitude detection thresholds set to exceed noise values. In most cases the threshold was set at $\sim 5 \mathrm{pA}$. Events were automatically selected, analyzed for double peaks, and then visually inspected and confirmed. Event amplitude histograms were generated and compared with the noise histogram to ensure that they did not overlap. Mean and median frequency $(\mathrm{Hz})$, amplitude $(\mathrm{pA})$, rise time $(10-90 \%, \mathrm{~ms})$, and holding current (pA) were measured for each cell and plotted in a summary table by the MiniAnalysis program. An averaged trace from $\sim 200$ events was fitted with a double exponential function, and subsequently fast and slow components of the decay phase were computed.

Following a stable baseline, drug was added and events recorded for 15-20 min. The last minute of each 3-min interval was analyzed. For experiments in which a single pharmacological agent was added, the baseline measurements were compared with the maximum steady-state response (in either direction) elicited by the drug using paired $t$-tests. For experiments in which there were multiple drugs added to a neuron, repeated-measures one-way ANOVAs with the post hoc Student-Newman-Keuls $t$-tests were performed. One-way ANOVAs with post hoc t-tests were performed for between-group comparisons using SigmaStat 3.0 software (SPSS, Chicago, IL) or Excel 
(Microsoft, Bellevue, WA). Repeated-measures two-way ANOVAs were used to compare the effect of strain and drug on mIPSCs. Statistical tests are reported for raw data measurements. A result was considered significant with a probability of $p<0.05$. Results are reported as means \pm SEM. Unless otherwise indicated, $N$ s are reported as number of cells. For each set of electrophysiology experiments, data were collected from a minimum of three animals, but more typically was collected from more than five animals.

Specifically for CRF and Ucn II experiments on GABA mIPSC activity conducted in 5-HT and non-5-HT cells of the DRN, data collected from WKY rats are presented next to previously published data from SD rats (see Kirby et al, 2008). The data from the previously published work were collected in parallel to the data collected from WKY rats on adjacent rigs on the same day or interleaved on different days throughout the same year. The data from both SD and WKY rats for the mRNA analysis, cellular characteristics, 5-carboxyamidotryptamine (5-CT), zolpidem, loreclezole, and ethanol experiments as well as the CRF experiments conducted in the MRN are all new to this manuscript.

\section{Drugs}

All chemicals for making the ACSF, electrolyte solution, L-tryptophan, antalarmin, 5-CT, and ethanol were obtained from Sigma-Aldrich or Fisher Scientific. DNQX, zolpidem, and loreclezole were purchased from Tocris (St Louis, MO) and TTX was obtained from Calbiochem (San Diego, CA). Antalarmin and DNQX were dissolved in DMSO (final DMSO concentration in bath $0.015 \%$ ). oCRF, Ucn II, and antisauvagine 30 were generously supplied by Dr Jean Rivier of the Clayton Foundation Laboratories for Peptide Biology, The Salk Institute (La Jolla, CA).

\section{RESULTS}

Figure 1 contains high-power photomicrographs of a 5-HTand a non-5-HT-containing cell in the DRN. The left panel contains biocytin-labeled cells, the middle panel is the TPH-stained cells, and the right panel contains the merged images.

\section{LCM and RNA Analysis}

LCM techniques were implemented to isolate TPH-positive cells from the heterogeneous cell population in the DRN. Following microdissection, RNA was extracted from 5-HTcontaining cells in the DRN of SD and WKY rats. Table 1 represents a subpopulation of measurements taken from the two strains. Values are listed as the fraction of RNA against $\beta$-actin, percentage change from SD to WKY as well as $p$-values for unpaired $t$-tests. We focused our analysis on mRNA that encode for proteins known to have a role in stress responses, anxiety, depression, or addiction, and also those critical for regulating the excitability of DRN neurons. In 5-HT neurons in the DRN of WKY rats, there was a significant reduction (66\% decrease) in mRNA encoding the predominant isoform of TPH expressed in the brain, $\mathrm{TPH} 2$, compared with SD rats. Differences in 5-HT receptor mRNA included that encoding for 5-HT1A, 5-HT1B, 5-HT1D, 5-HT2A, 5-HT2B, 5-HT6, and 5-HT7A. Notably, 5 -HT neurons in the DRN of WKY rats demonstrated a significant reduction in 5-HT1A and 5-HT6 receptor mRNA (21 and $8 \%$, respectively), and there was an $87 \%$ increase in 5-HT7A mRNA. The CRF R1 receptor mRNA expression was not significantly different based on strain; however, there was a $54 \%$ increase in CRF R2 mRNA expression in $\mathrm{WKY}$ rats. There was relatively little expression of mineralocorticoid receptor (MR) mRNA in the DRN. Moreover, although glucocorticoid receptors (GRs) were expressed

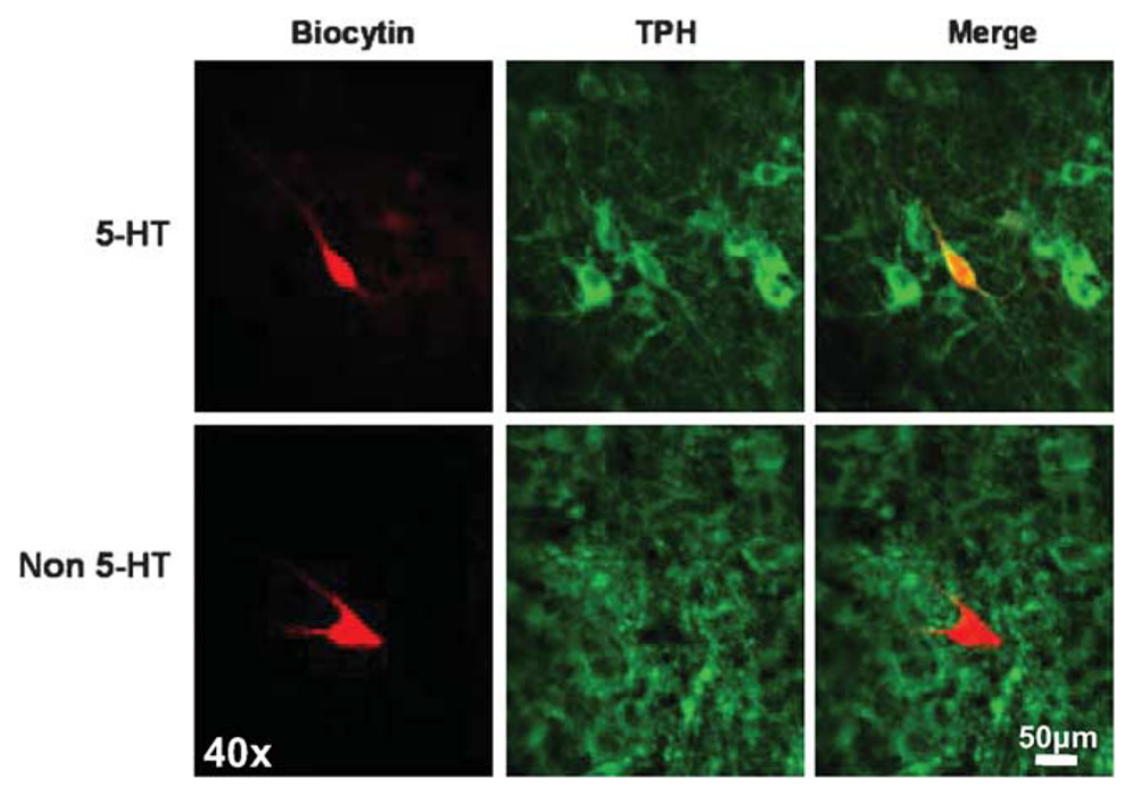

Figure I Immunohistochemical identification of 5-HT- and non-5-HT-containing neurons. Immunofluorescent photomicrographs of recorded neurons filled with biocytin (red) and co-stained for tryptophan hydroxylase (TPH) (green). The merged image is depicted in the left panels. Recorded neurons colocalized with TPH were classified as 5-HT containing (top panel). Neurons without TPH staining that were surrounded by TPH-positive cells in the same plane of focus were classified as non-5-HT containing (bottom panel). 
Table I Normalized aRNA Levels That Encode for Anxiety- and Depression-Related Proteins in 5-HT DRN Neurons of SD vs WKY Rats

\begin{tabular}{|c|c|c|c|c|c|c|}
\hline Name & Average & SEM & Average & SEM & $\begin{array}{c}\% \text { Change } \\
\text { WKY/SD *100 }\end{array}$ & $\begin{array}{c}\text { t-test } \\
P \text {-value }\end{array}$ \\
\hline $5-\mathrm{HT} \mid \mathrm{A}^{*}$ & 0.775 & 0.029 & 0.612 & 0.055 & 79 & 0.04 \\
\hline 5-HT IB & 0.007 & 0.003 & 0 & 0 & $N / A$ & NS \\
\hline 5-HT ID* & 0.013 & 0.005 & 0 & 0 & $N / A$ & 0.037 \\
\hline 5-HT 7A** & 0.015 & 0.001 & 0.028 & 0.004 & 187 & 0.002 \\
\hline TPH I & 0.002 & 0.001 & 0.006 & 0.001 & 279.5 & 0.058 \\
\hline TPH 2****** & 0.157 & 0.007 & 0.051 & 0.017 & 32 & 0.001 \\
\hline Adcy 2*** & 0.126 & 0.005 & $0.07 \mid$ & 0.012 & 56 & 0.006 \\
\hline GABA-A $\left.\alpha\right|^{*}$ & 0.947 & 0.026 & 0.837 & 0.026 & 88 & 0.023 \\
\hline GABA-A $\alpha 2$ & 0.779 & 0.052 & 0.636 & 0.077 & 82 & NS \\
\hline GABA-A $\alpha 4$ & 0.783 & 0.051 & 0.668 & 0.052 & 85 & NS \\
\hline GABA-A $\alpha 5$ & 0.714 & 0.058 & 0.809 & 0.075 & 113 & NS \\
\hline GABA-A $\beta 1$ & 0.6 & 0.037 & 0.577 & 0.138 & 96 & NS \\
\hline GABA-A $\beta 2$ & 0.625 & 0.056 & 0.653 & 0.079 & 104 & NS \\
\hline GABA-A $\beta 3$ ***** & 0.14 & 0.009 & 0.017 & 0.007 & 12 & 0.001 \\
\hline GABA-A $\gamma 2$ & 0.761 & 0.064 & 0.692 & 0.063 & 91 & NS \\
\hline
\end{tabular}

Abbreviation: N, number of animals.

Amplified RNA levels have been normalized to $\beta$-actin levels. Data are expressed as the mean \pm SEM.

*Significant difference (in bold) between SD and WKY 5-HT-containing cells (* $p<0.05$, ** $p<0.0$ I, *** $p<0.00$ I) by unpaired $t$-test.

in the DRN, there was not a significant difference in expression between strains. Finally, there was a significant reduction (12\%) of $\mathrm{GABA}_{\mathrm{A}} \alpha 1$ subunits and remarkably an $88 \%$ reduction in $\mathrm{GABA}_{\mathrm{A}} \beta 3$ subunits in 5 - $\mathrm{HT}$ neurons of WKY rats.

Electrophysiological studies were focused on receptormediated responses with known functional effects that have been well characterized in either the DRN or other regions, namely, 5-HT1A, CRF R1 and R2, and $\mathrm{GABA}_{\mathrm{A}}$ subunit effects. Electrophysiological data were recorded from both 5-HT- and non-5-HT-containing neurons and results are reported for both cell types in the text and tables; however, only data from 5-HT neurons are shown graphically.

\section{Cellular Characteristics of 5-HT and Non-5-HT Cells in the DRN of SD and WKY Rats}

Using current clamp configuration, cellular characteristics were recorded from 5-HT- and non-5-HT-containing cells in the DRN of SD and WKY rats. Table 2 contains the summary data (means \pm SEM). The cellular characteristics of the $5-\mathrm{HT}$ and non-5-HT neurons in SD rats were similar to those previously reported (Beck et al, 2004). However, 5-HT cells of WKY rats had a more hyperpolarized resting membrane potential (RMP) when compared with SD 5-HT cells $(p<0.05)$, suggesting a decreased intrinsic excitability of WKY 5-HT neurons. Interestingly, there were no differences in either membrane input resistance or tau between SD and
WKY 5-HT neurons. The response to 5-HT1A receptor activation was also assessed. A saturating concentration of the 5-HT1,7 receptor agonist 5-CT (100 nM) was bath applied to assess the hyperpolarization $(\mathrm{mV})$ associated with 5-HT1A receptor activation (Beck et al, 2004). Based on the mRNA data, we hypothesized that 5-HT neurons of WKY rats would show an attenuated response to 5-HT1A receptor activation. The response to 5-CT administration was not different between SD and WKY rats for both 5-HT- and non5-HT-containing neurons in the DRN. However, using a criterion of $5 \mathrm{mV}$ hyperpolarization minimum, there was a trend for a difference in the percentage of neurons exhibiting a 5-HT1A receptor-mediated response, that is, $85 \%$ for neurons recorded from SD rats, but only $75 \%$ for neurons from WKY rats. It is possible that a nonsaturating concentration of 5-CT would reveal a more substantial difference between strains. Additionally, there was a difference between the non-5-HT neurons, with $50 \%$ of the neurons from SD rats exhibiting a response, but only $20 \%$ of the neurons from the WKY rats. The $\chi^{2}$ analysis revealed that the data were not significant $(p=0.07)$.

\section{Functional Effects of $\mathrm{GABA}_{\mathrm{A}}$ Subunit Changes in WKY 5-HT Neurons}

The rise and decay kinetics of the mIPSC are entirely dependent on the $\mathrm{GABA}_{\mathrm{A}}$ receptor subunit composition. The RNA data indicated only a $12 \%$ reduction in $\alpha 1$ subunit 
expression, yet demonstrated an $88 \%$ reduction in $\beta 3$ subunit expression in WKY rats. Based on previous studies from $\beta 3^{-1-}$ mice (Ramadan et al, 2003), we hypothesized that mIPSCs recorded from 5-HT neurons in the DRN of WKY rats would have significantly faster decay kinetics than SD rats. The baseline data from all of the experiments were combined for the analysis of baseline mIPSC parameters. There were no significant differences in baseline mIPSC characteristics between experiments from the same cell type and strain. The mIPSC parameters from SD and WKY 5-HT and non-5-HT neurons are presented in Table 3. A one-way ANOVA with post hoc $t$-test revealed that non-5-HT neurons in SD rats exhibited significantly larger mIPSC amplitude compared with all other groups. However, this was the only significant difference in basal mIPSC properties. Surprisingly, there were no significant differences specifically in rise or decay kinetics in the mIPSC measured between SD and WKY 5-HT neurons. There were also no significant differences in mIPSC frequency or amplitude between 5-HT neurons based on rat strain, suggesting a similar probability of release of GABA from presynaptic terminals as well as similar basal receptor occupancy/receptor density.

The $\beta 3$ subunit is important in the activation of the receptor, and therefore the difference between SD and WKY rats may manifest when the receptor is activated by selective agonists. To confirm the mRNA data, we used standard immunohistochemistry protocols to assess $\beta 3$ protein expression on 5-HT neurons. Consistent with the quantitative mRNA data, qualitative inspection of changes in $\mathrm{GABA}_{\mathrm{A}}$ $\beta 3$ immunohistochemistry in SD and WKY rats revealed an overall reduction in fluorescent intensity and $\beta 3$-positive cells in WKY animals (Supplementary Figure S1). Despite the fact that we did not see a change in basal mIPSC kinetics between $\mathrm{SD}$ and WKY 5-HT neurons, it is possible that this difference in $\mathrm{GABA}_{\mathrm{A}}$ receptor subunit expression would manifest as a change in pharmacological efficacy.

To test the hypothesis that there was a functional effect of $\mathrm{GABA}_{\mathrm{A}} \beta 3$ reduction in WKY rats, loreclezole, an anticonvulsant and $\mathrm{GABA}_{\mathrm{A}}$ modulator that selectively binds to $\beta 2 / 3$ subunits, was bath applied. We reasoned that as there was no change in $\beta 2 \mathrm{mRNA}$ expression, the potential differences in loreclezole $(10 \mu \mathrm{M})$-mediated mIPSC prolongation would be because of alterations in $\beta 3$ expression. Loreclezole experiments were conducted only in 5-HT neurons. Figure 2a depicts representative traces before and after application of loreclezole in 5-HT neurons of SD and WKY rats. Loreclezole did not significantly increase mIPSC frequency in SD or WKY rats, nor did it significantly augment mIPSC amplitude $(N=7$ for both SD and WKY; Supplementary Table S1 and Figure $2 \mathrm{~b}$ ). Loreclezole significantly prolonged mIPSC decay only in SD 5-HT neurons, but not in WKY 5-HT neurons (Supplementary Table S1 and Figure 2c). Based on these data, we concluded that the large reduction in $\mathrm{GABA}_{\mathrm{A}} \beta 3 \mathrm{mRNA}$ in WKY 5-HT neurons results in a functional decrease in $\mathrm{GABA}_{\mathrm{A}}$ receptor activation.

The alteration in $\beta 3$ function may have implications for the functional effects of the $\alpha 1$ subunit, although only a small change in $\alpha 1$ subunit expression itself was found. In hippocampal cultures from $\beta 3^{-/-}$mice, there was a significant enhancement in the efficacy of zolpidem that allosterically binds selectively to $\alpha 1$ containing $\mathrm{GABA}_{\mathrm{A}}$ 
Table 3 mIPSC Characteristics for 5-HT and Non-5-HT Neurons in the DRN of SD and WKY Rats

\begin{tabular}{lccccc}
\hline Cell type & Frequency $(\mathbf{H z})$ & Amplitude (pA) & Rise time (msec) & Fast decay time (msec) & Slow decay time (msec) \\
\hline SD 5-HT (N=77) & $6.9 \pm 0.4$ & $17.1 \pm 0.7$ & $1.3 \pm 0.04$ & $3.9 \pm 0.3$ & $35.9 \pm 5.9$ \\
SD non-5-HT (N=35) & $5.7 \pm 0.5$ & $23.3 \pm 1.9^{\mathrm{a}}$ & $1.3 \pm 0.05$ & $3.7 \pm 0.2$ & $18.7 \pm 2.8$ \\
WKY 5-HT (N=62) & $6.1 \pm 0.5$ & $18.3 \pm 0.9$ & $1.3 \pm 0.05$ & $3.9 \pm 0.2$ & $54.9 \pm 17.7$ \\
WKY non-5-HT (N=26) & $4.9 \pm 0.5$ & $16.6 \pm 1.0$ & $1.5 \pm 0.06$ & $3.6 \pm 0.2$ & $26.1 \pm 5.4$ \\
\hline
\end{tabular}

${ }^{a}$ Significantly different from all other groups by Kruskal-Wallis ANOVA, Dunn's follow-up $p<0.05$.

a Loreclezole (10 uM)
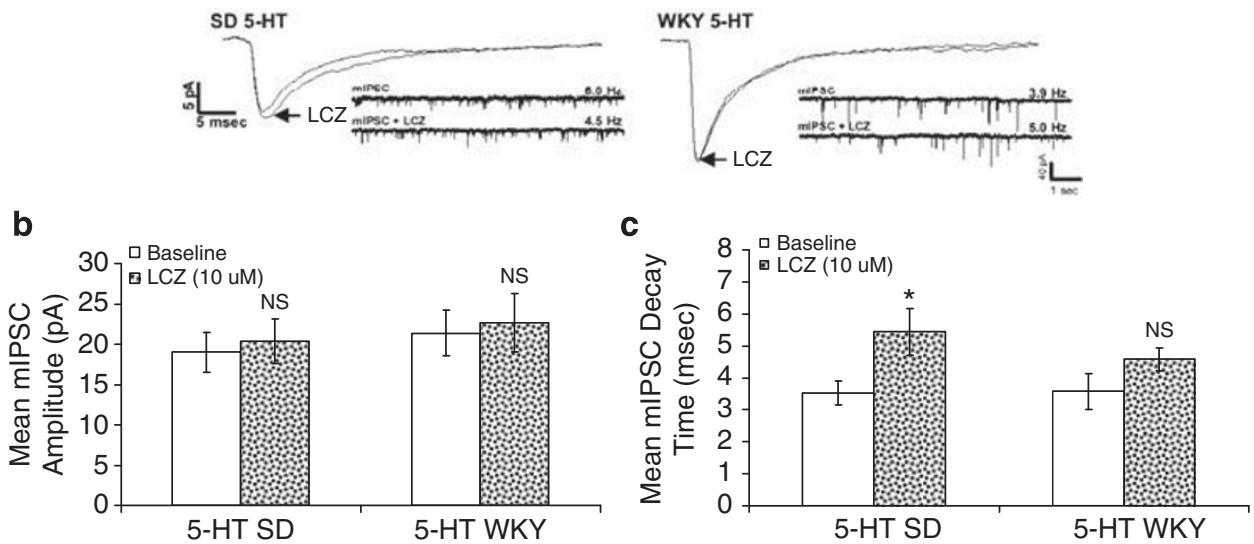

Figure 2 Response to loreclezole is absent in 5-HT neurons of WKY rats. (a) A representative averaged mIPSC and trace (inset) from a 5-HT neuron in a SD (left) or WKY (right) rat before and after $10 \mu \mathrm{M}$ loreclezole application, an anti-convulsant that selectively binds to the $\beta 2 / 3$ subunits. (b) Loreclezole had no effect on mIPSC amplitude in either SD or WKY rats ( $p>0.05)$, (c) and only significantly prolonged mIPSC fast decay in SD animals $(p<0.05)$, but not WKY animals $(p>0.05)$.

channels, because of loss of $\alpha 2 / 3$ subunit expression at the cell surface. Similar to $\beta 3^{-/-}$mice, we found a zolpidemelicited increase in mIPSC amplitude in 5-HT neurons of WKY rats compared with SD rats (Supplementary Table S1).

\section{CRF Receptor Activation Effects on mIPSCs in Cells Recorded from the DRN of WKY Rats}

In a recent paper from our laboratory we demonstrated that CRF R1 activation enhances GABAergic synaptic transmission both pre- and post-synaptically in 5-HT-containing neurons in the DRN of SD rats (Kirby et al, 2008). Additionally, in both 5-HT and non-5-HT neurons, CRF produced a small, yet physiologically relevant, inward current, through activation of different receptors: CRF R2 in 5-HT neurons and CRF R1 in non-5-HT neurons. It has been demonstrated that WKY rats are behaviorally similar to rats that have been previously exposed to stressors and, therefore, we predicted that there would be an attenuation of the in vitro CRF effects on GABAergic synaptic transmission and cell excitability established by Kirby et al (2008). However, in light of the mRNA data, we further predicted that some, if not all, of the CRF R2 effects may be retained as there was a significant upregulation of CRF R2 mRNA in 5-HT neurons of WKY rats.

The same protocol and concentrations of oCRF (selective R1 agonist) and Ucn II (selective R2 agonist) were used as described in Kirby et al (2008). Data were collected from WKY rats in parallel using the same drugs and stock solutions. Therefore, the data from the SD rats are the controls for the data obtained from the WKY rats (see Materials and Methods).

Figure 3a displays representative traces (left) and the averaged mIPSC (right) recorded from cells before and after the administration of oCRF from SD 5-HT (upper panel) and WKY 5-HT (lower panel) neurons. Figure $3 \mathrm{~b}$ and c contains summary graphs of the mIPSC frequency (Figure 3b) and amplitude (Figure 3c) following oCRF bath application for 5-HT neurons recorded in the DRN of SD and WKY rats $(N=26$ and 19 , respectively). In direct contrast to our findings in SD rats, oCRF did not increase mIPSC frequency or amplitude in neurons recorded from WKY rats (Supplementary Table S2 and Figure $3 b$ and c). Interestingly, in non-5-HT WKY neurons, oCRF did significantly increase both mIPSC frequency and amplitude $(p<0.05, N=7)$; these effects were not apparent in non-5HT neurons in SD rats (Supplementary Table S2).

In a separate set of experiments, the selective CRF R2 agonist, Ucn II, was bath applied to the slice. Figure 4a contains representative traces (left) and averaged mIPSCs before and after Ucn II administration in recordings made from 5-HT neurons in SD (upper panel) and WKY (lower panel) rats. In SD rats, Ucn II had no effect on frequency but significantly increased the amplitude of mIPSCs $(p<0.01, N=17$; Figure $4 \mathrm{c}$ and Supplementary Table S2). Similarly to what was reported in SD rats, Ucn II had no effect on mIPSC frequency in WKY 5-HT neurons $(N=13$; Figure 4b). Interestingly, similarly to SD 5-HT neurons, Ucn 

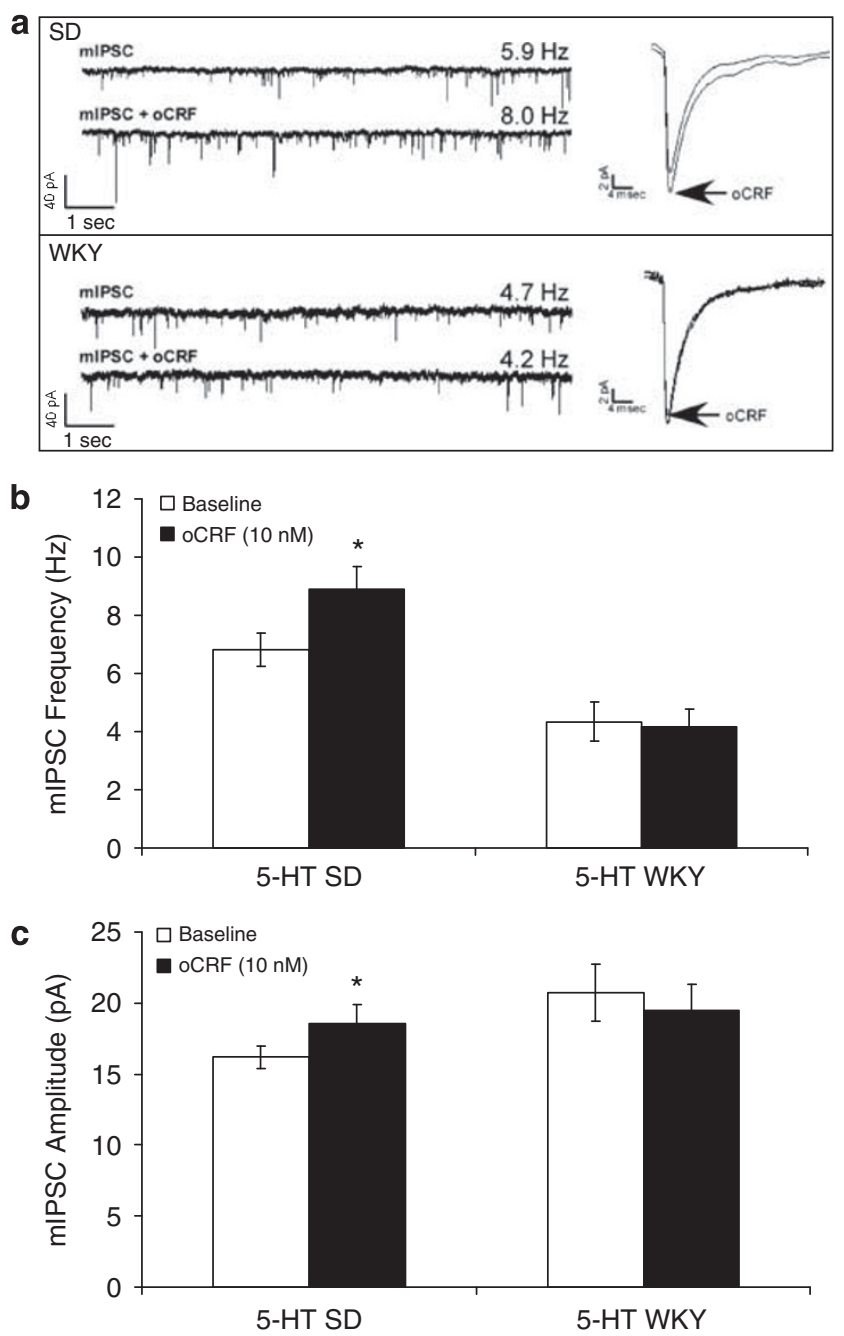

Figure 3 CRF responses are attenuated in 5-HT DRN neurons of WKY rats. (a) Representative traces (left) and averaged mIPSC (right) from recordings made from 5-HT neurons of SD (top) and WKY (bottom) rats before and after $10 \mathrm{nM}$ oCRF bath application. (b) Summary bar graph depicting the baseline mean mIPSC frequency and the change following oCRF administration to neurons recorded from SD and WKY rats. oCRF significantly increased mIPSC frequency $(p<0.05)$. This effect was absent in WKY rats $(p>0.05)$. (c) Summary bar graph depicting the baseline mean mIPSC amplitude and change following OCRF in SD and WKY rats. OCRF significantly increased mIPSC amplitude $(p<0.05)$. This effect was absent in WKY rats $(p>0.05)$.

II significantly augmented mIPSC amplitude in WKY 5-HT neurons (Figure 4c). Kirby et al (2008) reported no effect of Ucn II on mIPSC frequency or amplitude in non-5-HTcontaining neurons of SD rats. However, Ucn II did significantly augment mIPSC amplitude in WKY non-5HT neurons $(p<0.05, N=8$; Supplementary Table S2).

Therefore, in the WKY stress-hyperresponsive rats, the CRF R1-mediated increase in frequency was attenuated in 5HT neurons, but enhanced in non-5-HT neurons. Ucn II significantly increased mIPSC amplitude in WKY 5-HTcontaining cells. In WKY non-5-HT neurons, both oCRF and Ucn II augmented mIPSC amplitude. Thus, in the DRN 5-HT neurons of stress-hyperresponsive rats, the CRF R2mediated response on GABAergic synaptic transmission was retained, but the CRF R1 response eliminated. More- a
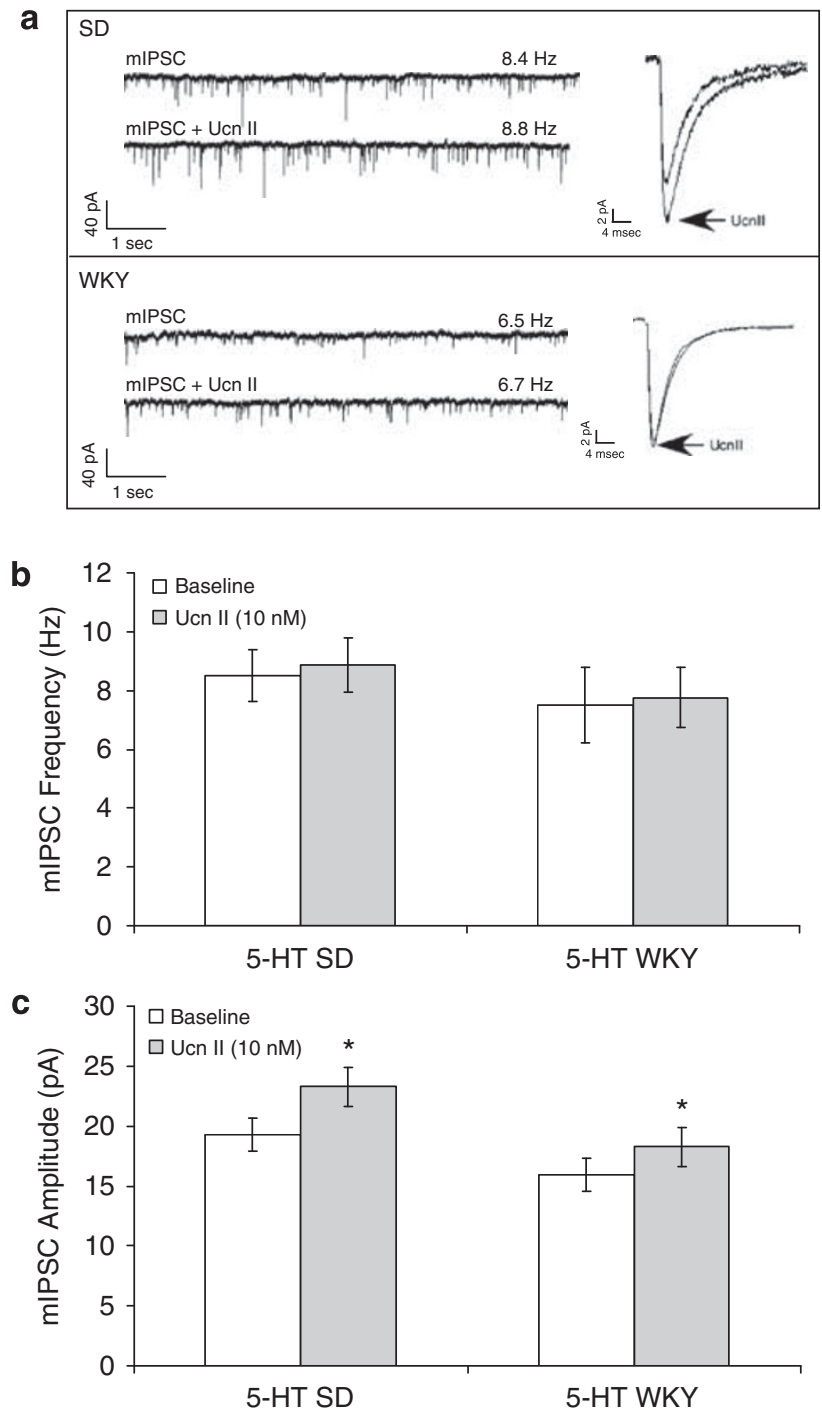

Figure 4 The effects of the selective CRF R2 agonist Ucn II on mIPSC amplitude were retained in WKY rats. (a) Representative traces (left) and averaged mIPSC (right) from recordings made from 5-HT neurons of SD (top) and WKY (bottom) rats before and following $10 \mathrm{nM} \mathrm{Ucn} \mathrm{II} \mathrm{bath}$ application. (b) Summary bar graph depicting the baseline mean mIPSC frequency and the change following Ucn II administration to neurons recorded from SD and WKY rats. Urocortin II had no effect on mIPSC frequency in SD rats and likewise had no effect on 5-HT neurons recorded from WKY rats $(p>0.05)$. (c) Summary bar graph depicting the baseline mean mIPSC amplitude and change in amplitude following $U \mathrm{cn} \|$ in neurons recorded from SD and WKY rats. Ucn II significantly augmented mIPSC amplitude in 5-HT neurons of both SD and WKY rats $(p<0.05)$.

over, CRF modulation of GABAergic transmission that was not seen in SD non-5-HT neurons was significantly enhanced in non-5-HT neurons in the WKY rats.

This difference in CRF response between strains is specific to the DRN. In a set of control experiments conducted in the neighboring ventral serotonergic structure, the MRN, CRF was found to augment mIPSC amplitude in 5-HT cells of both SD and WKY rats (Supplementary Figure S2). Despite evidence that this structure is also involved in affective behavior, CRF responsiveness of these cells was retained in WKY rats, suggesting a regional specificity as opposed to a global change. 


\section{oCRF and Ucn II Do Not Alter the Inward Current in WKY Rats}

In SD animals, oCRF and Ucn II significantly increased the inward current in 5-HT-containing cells. Pretreatment with the CRF R2 antagonist ASVG-30, but not the CRF R1 antagonist antalarmin, is able to block the effect of oCRF on inward current. This evidence suggests that this effect is mediated by the CRF R2 receptor (Kirby et al, 2008). Only oCRF, but not Ucn II, significantly increased the inward current in non-5-HT cells in an antalarmin-sensitive manner, suggesting that in this cell type CRF R1 receptors mediate the effect. In this study, the effects of oCRF or Ucn II on inward current were not apparent in either 5-HT- or non-5-HT-containing cells of WKY rats. The CRF R1- and CRF R2-mediated increase in inward current was absent in non-5-HT- and 5-HT-containing neurons from WKY rats, respectively. Thus, the net effect of CRF receptor activation on 5-HT neurons in WKY rats was selective to an enhancement of $\mathrm{GABA}_{\mathrm{A}}$ receptor-mediated currents, without a simultaneous increase in GABA release.

\section{The GABAmimetic Effects of Ethanol (EtOH) on 5-HT Neurons in DRN of SD and WKY Rats}

Along with demonstrating a global stress hyperresponsivity, WKY rats also show an increase in alcohol preference (Pare et al, 1999). EtOH depresses DRN firing rates in vivo and presumably depresses 5 -HT release in the forebrain (Pistis et al, 1997). It is possible that DRN dysregulation and subsequent abnormal physiological responses to $\mathrm{EtOH}$ in the DRN may be in part responsible for the behavioral increase in alcohol preference documented in WKY rats. Physiologically relevant concentrations of EtOH, 10$100 \mathrm{mM}$, have GABAmimetic effects via enhancement of mIPSC frequency or amplitude in in vitro slices made of limbic regions such as the central amygdala (Nie et al, 2004). Moreover, EtOH-mediated effects can be blocked by pretreatment of the CRF R1 selective antagonist antalarmin and is also not apparent in CRF $\mathrm{R}^{-I-}$ mice. We reasoned that it was possible, given the alterations in $\mathrm{GABA}_{\mathrm{A}}$ subunit expression and pharmacological sensitivity as well as attenuation of CRF R1-mediated enhancement of GABAergic synaptic transmission, that a midrange concentration of EtOH $(50 \mathrm{mM})$ would have disparate effects on $\mathrm{GABA}_{\mathrm{A}}$ mIPSC frequency and amplitude in 5-HT neurons from SD $v s$ WKY rats. We also wanted to determine if antalarmin pretreatment would have a similar block on the GABAmimetic effects of EtOH. Figure 5a shows representative traces from 5-HT neurons recorded from SD (Figure 5ai and aii) and WKY (Figure 5aiii) rats. In a separate set of SD rats, the slice was pretreated with antalarmin $(300 \mathrm{nM})$ following a baseline mIPSC recording, but before EtOH treatment. Similar to what was reported in our previous work, there was a trend for antalarmin to increase mIPSC amplitude $(p=0.08)$. Figure $5 \mathrm{~b}$ and $\mathrm{c}$ contains summary bar graphs of the change in frequency and amplitude from baseline following $\mathrm{EtOH}(50 \mathrm{mM})$ bath application. We found that $\mathrm{EtOH}(50 \mathrm{mM})$ significantly enhanced mIPSC frequency and amplitude $(p<0.05$ in both SD and WKY DRN 5-HT neurons, $N=10$ and 9 , respectively), yet there was no significant effect of strain (two-way repeated-measures ANOVA, $p>0.05$; Supplementary Table S2 and Figure 5b and c). Pretreatment with Antalarmin had no effect on EtOH-mediated enhancement of mIPSC frequency, but did attenuate the EtOH effect on mIPSC amplitude (one-way repeated-measures ANOVA, $p<0.05$, baseline $v s$ antalarmin $p>0.05$, antalarmin $v s$ EtOH, $p>0.05 ; N=6$ ). This finding is consistent with other studies demonstrating an antalarmin block of EtOH GABAmimetic effects. It is also suggested that there were two different mechanisms underlying the EtOH effects on presynaptic release of GABA $v s$ postsynaptic enhancement of the amplitude. However, based on our comparison of SD with WKY rats in this set of experiments, we conclude that there is no appreciable
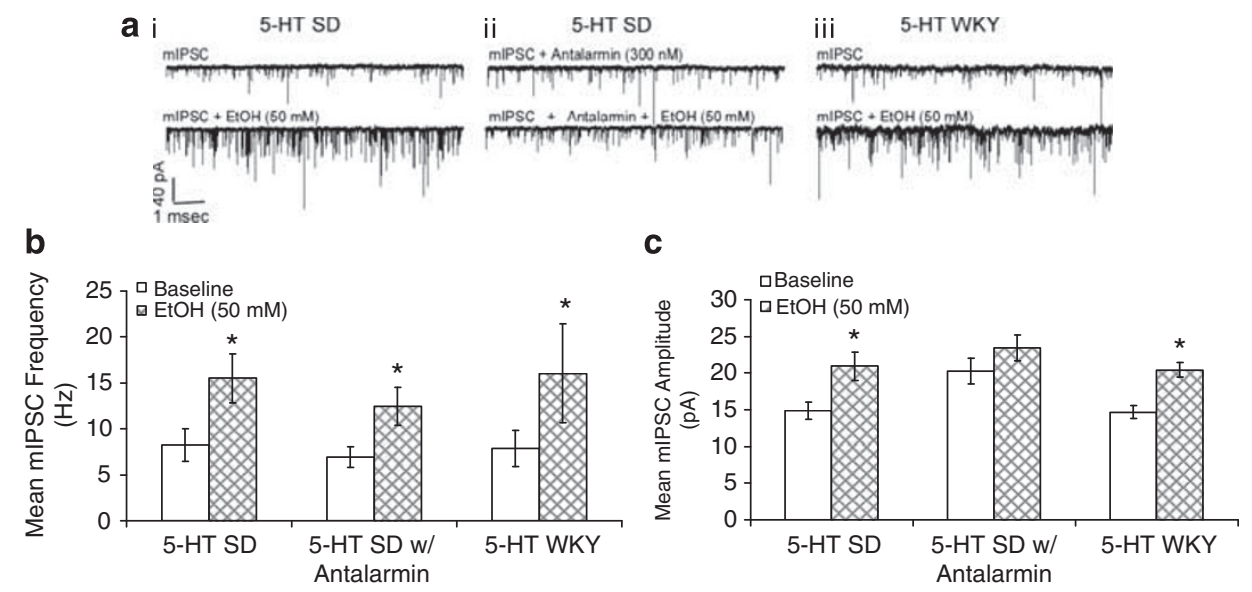

Figure 5 GABAmimetic effects of $\mathrm{EtOH}(50 \mathrm{mM})$ were not different in 5-HT neurons from SD and WKY rats. (a) Representative traces from recordings made from 5-HT neurons of SD (ai, aii) and WKY (aiii) rats before and after application of $50 \mathrm{mM}$ EtOH. In the middle panel (aii), the top trace contains mIPSC data with the selective CRF RI antagonist, antalarmin (300 nM) on board, and the bottom trace represents the effect of EtOH on mIPSCs in the presence of antalarmin. (b) Summary bar graph of the change in mIPSC frequency following EtOH application. EtOH significantly enhanced mIPSC frequency similarly in SD and WKY rats $(p<0.05)$ and this effect was not significantly blocked by antalarmin. (c) Summary bar graph of the change in mIPSC amplitude following EtOH application. EtOH significantly enhanced mIPSC amplitude similarly in SD and WKY rats $(p<0.05)$, and this effect was significantly attenuated by antalarmin. 
difference in the EtOH response in this nucleus in stresshyperresponsive rats.

\section{DISCUSSION}

The major premise of this investigation was that DRN intrinsic excitability and its modulation is altered in pathological stress states that may in turn lead to psychiatric disorders such as MDD and generalized anxiety disorder. The objective of this study was to use a multilevel approach to investigate differences in the regulation of 5-HT-containing neurons from the DRN, an area critical in mediating stress responses, in a stress-hyperresponsive animal model, the WKY rat (Pare, 1993, 1989a, 1994a, 1994b, 2000; Pare and Redei, 1993a; Pare and Tejani-Butt, 1996; Pare et al, 1999). Although many behavioral studies have been conducted on these animals, very few have been done addressing possible cellular mechanisms underlying this stress hyperresponsivity. The behavioral studies demonstrated differences in all three major monoaminergic systems; that is, dopamine, norepinephrine, and serotonin (Conti et al, 1997; Lopez-Rubalcava and Lucki, 2000; Pare and Tejani-Butt, 1996; Pearson et al, 2006; Tejani-Butt et al, 1994). The DRN is critical in mediating responses to uncontrollable stress (Maier and Watkins, 2005) and is functionally altered following in vivo stressor exposure (Kirby et al, 2007; Price et al, 2002). We, therefore, focused our attention to differences in mRNA expression, protein expression, and physiology in the DRN of WKY rats.

Differences in the mRNA levels of 5-HT receptors, effectors, synthesizing enzymes, and $\mathrm{GABA}_{\mathrm{A}}$ receptor subunits were found between the WKY and SD rats. The RMP was the only membrane property that was significantly different between the 5-HT- or non-5-HT-containing neurons of the DRN between the WKY and SD rats. The proportion of neurons demonstrating a 5-HT1A response was less in both 5-HT and non-5-HT neurons from WKY rats. Responses mediated by the stress hormone CRF were significantly different and there were differences in the responses mediated by selective benzodiazepines interacting with the $\mathrm{GABA}_{\mathrm{A}}$ receptor. Interestingly, there were no differences found in the response to alcohol.

\section{Decrease in TPH2 Production and Intrinsic Excitability in 5-HT Neurons}

Significant differences were found in mRNA encoding for a variety of depression- and anxiety-related proteins as well as proteins necessary for GPCR downstream signaling in 5-HT neurons of WKY rats. There are several studies that have examined differences in mRNA expression in different animal models of stress hyperresponsivity or following various behavioral manipulations to elicit stress. However, these studies do not selectively examine differences specifically in the 5-HT neurons, but throughout the entire heterogeneous DRN. Therefore, LCM and mRNA amplification techniques were employed to look at differences in mRNA expression in 5-HT neurons of SD compared with WKY rats.

A recent study by Scholl et al (2010) demonstrated a significant reduction in basal 5-HT levels in several brain limbic brain regions (ie, basolateral amygdala, nucleus accumbens shell, substantia nigra, dorsal raphe, and hypothalamus) in WKY rats compared with SD controls, with comparable 5-HT turnover rates. Consistent with this finding, WKY rats were found to have a significant reduction in TPH2 mRNA expression in DRN neurons compared with SD rats. Recent attention has been given to the relationship between TPH2 gene polymorphisms and mRNA expression and stress, anxiety, and depression. However, thus far, various studies have presented conflicting data and the relevance of changes in TPH2 expression to maladaptive affective behavior remains unclear (McEuen et al, 2008; Shishkina et al, 2008; Lowry et al, 2008; Clark et al, 2007; Abumaria et al, 2008; Gizatullin et al, 2008). No studies have been conducted examining the actual physiological relevance of changes in TPH2 production, that is, changes in the levels of 5-HT in the raphe and forebrain. It is likely that the level of TPH2 expression is correlated with the progression of psychiatric disease. For example, the initial etiology of depression-like behavior may be, in part, due to low expression levels of TPH2, which would be consistent with low levels of 5-HT found in the forebrain of depressed patients (Coppen and Doogan, 1988; Deakin, 1991; Grahame-Smith, 1989).

$\mathrm{TPH} 2$ is the predominant isoform expressed in 5-HT neurons; however, although not statistically significant, there was a strong trend of a 2.5 -fold increase in TPH1 expression in WKY rats. This increase in TPH1 matches most closely the findings of Abumaria et al (2008), who demonstrated that chronic daily restraint stress significantly increased TPH1 expression in the DRN 2.5-fold. Perhaps, TPH1 increases activity when TPH2 is not functioning. Future studies must address the functional consequences of the relative contributions by TPH1 and TPH2 on $5-\mathrm{HT}$ release, especially in models of stress.

The intrinsic excitability and synaptic input to the DRN are both important in regulating the firing rate of $5-\mathrm{HT}$ neurons and the subsequent release of 5- $\mathrm{HT}$ into forebrain regions. The 5-HT neurons in the DRN of WKY rats had a significantly hyperpolarized RMP, yet similar action potential characteristics, tau, and membrane resistance. Therefore, given an equal excitatory drive, the firing rate and subsequent release of 5-HT into the forebrain is likely lower in WKY rats. This lower neuronal excitability coupled by a dramatic reduction in TPH2 mRNA expression would be consistent with a lower level of 5-HT in the forebrain, similar to that seen in depressed patients (Coppen and Doogan, 1988; Deakin, 1991; Grahame-Smith, 1989).

\section{Autoreceptor Inhibition by 5-HT1A Receptor Was Altered in WKY Rats}

The levels of the 5-HT1A autoreceptor have recently been shown to determine vulnerability to stress and response to antidepressant treatments (Richardson-Jones et al, 2010). A significant decrease was found in mRNA expression of 5-HT1A and 5-HT6 receptors in WKY rats, with almost a twofold increase in 5-HT7 receptor expression. The 5-HT1A receptor is coupled to an inward rectifying $\mathrm{K}^{+}$channel and is important in regulating the excitability of the DRN (Penington et al, 1993; Beck et al, 2004). The small difference in 5-HT1A receptor expression was not sufficient to 
change the response of $5-\mathrm{HT}$ neurons in WKY rats to a saturating concentration of 5-CT (selective 5-HT1,7 agonist) application. However, there was a trend in the ratio of neurons demonstrating a response to 5-CT, with both the 5-HT and non-5-HT neurons from WKY neurons having a lower percentage. Future studies should be conducted to examine the response of these neurons over a broad range of nonsaturating concentrations and within the different subfields of the raphe, as we have previously demonstrated that the 5-HT1A response magnitude is greater in the different DRN subfields (Beck et al, 2004; Crawford et al, 2010).

\section{$\mathrm{GABA}_{\mathrm{A}}$ Subunit Expression, Function, and Pharmacological Sensitivity}

5-HT neurons of the DRN receive GABAergic input from forebrain areas and from GABA neurons of the DRN that provide feedback information as well as control firing of the cells (Gervasoni et al 2000; Haddjeri et al 2000; Nishikawa and Scatton 1983, 1984, 1985). Stress exposure specifically increases c-Fos immunoreactivity of GABAergic neurons of the raphe (Roche et al, 2003). Moreover, manipulations of specific $\mathrm{GABA}_{\mathrm{A}}$ subunit conformations can result in anxiety-like behavior (Korpi and Sinkkonen, 2006). Several FDA-approved drugs are allosteric modulators of $\mathrm{GABA}_{\mathrm{A}}$ receptors that bind selectively to different subunits (Korpi and Sinkkonen, 2006; Mohler 2006). These compounds may act differently in a stress-hyperresponsive brain because of changes in subunit expression and composition. Therefore, we examined $\mathrm{GABA}_{\mathrm{A}}$ subunit RNA expression levels, the basal properties of GABAergic synaptic activity, and the response to $\mathrm{GABA}_{\mathrm{A}}$ selective drugs between $\mathrm{SD}$ and WKY rats. There was a small decrease in $\mathrm{GABA}_{\mathrm{A}} \alpha 1$ expression in WKY rats. There was a dramatic decrease in $\mathrm{GABA}_{\mathrm{A}} \beta 3$ expression, although there was a relatively low expression level. This is not surprising as it is the $\beta 2$ subunit that is ubiquitously expressed in all $\mathrm{GABA}_{\mathrm{A}}$ receptors. However, it is the $\beta 1$ and $\beta 3$ subunits that are critical for receptor trafficking and docking to the cell surface as well as phosphorylation of the receptor (Moss and Smart, 2001). Homanics et al (1997) found that $\beta 3^{-1-}$ mice demonstrated hypersensitivity to handling and other sensory stimuli as well as other neurological problems. The efficacy of an allosteric modulator, loreclezole, that binds selectively to the $\beta 2 / 3$ subunits was disrupted. Loreclezole prolonged mIPSC decay time only in 5-HT neurons of SD rats. This is direct evidence that there was a deficiency in $\beta 2 / 3$ cell surface expression in 5-HT neurons of WKY rats. Zolpidem augmented the mIPSC amplitude in 5-HT neurons of WKY rats approximately twice as much as in SD rats (42.3 vs $23.7 \%)$.

These findings suggest that although stress-hyperresponsive animals demonstrate changes in $\mathrm{GABA}_{\mathrm{A}}$ receptor subunit composition, this does not manifest in a functional change in basal GABAergic synaptic transmission. Therefore, stress-induced depressive-like behaviors cannot be due to maladaptive alterations in GABAergic synaptic transmission in the DRN. Loreclezole is an approved anticonvulsant therapy, whereas zolpidem (Ambien) is an approved sleep aid. Use of these compounds by individuals with depression or anxiety may have abnormal effects because of an altered cellular response in the serotonergic system.

\section{Alterations in CRF R1- and R2-Mediated Responses in WKY Rats}

A main principle underlying stress hyperresponsivity is that a dysregulation of the stress neurocircuitry involved in mediating an adaptive transient stress response occurs such that individuals respond in a maladaptive manner to acute mild stressors or neutral stimuli. Acute CRF application to the slice preparation at low concentrations may model an acute mild stressor. Therefore, assessing how these responses are altered in an animal model of depression that demonstrates behavioral hyperresponsivity to stressors provided an insight into some of the mechanisms underlying this dysregulation. Fibers containing CRF are apparent from the rostral to caudal DRN and cells of the DRN express both CRF R1 and CRF R2 (Kirby et al, 2000; Price et al, 1998; Price and Lucki, 2001; Day et al, 2004; Lukkes et al, 2008). Acute application of CRF to the DRN results in the modulation of 5-HT neuronal excitability. A major finding of this study is that some of these acute CRF responses were attenuated in WKY rats.

In control SD rats, CRF enhances both mIPSC frequency and decreases evoked IPSC paired pulse ratio, thereby increasing the probability of release of GABA from presynaptic terminals that synapse on 5-HT neurons. This increase in GABA release is mediated by CRF $\mathrm{R} 1$ receptors located on GABAergic synaptic terminals (Kirby et al, 2008). Despite similar mRNA expression levels of CRF R1 in the stress-hyperresponsive WKY and SD rats, the CRF R1 receptor-mediated increase in mIPSC frequency was absent in the 5-HT neurons of the DRN in the WKY rat. CRF R1 receptor-mediated postsynaptic responses were also attenuated in the WKY rat. The increase in mIPSC amplitude is mediated by both CRF R1 and R2 receptors (Kirby et al, 2008). In the 5-HT neurons recorded from the WKY rats, the CRF R1-mediated increase in mIPSC amplitude was absent.

There is a growing body of evidence suggesting that CRF $\mathrm{R} 2$ activation in specific brain regions (ie, lateral septum, dorsal raphe, and ventral tegmental area) is critical for encoding aversive stimuli under specific conditions in certain behavioral assays (ie, conditioned place aversion and stress-induced reinstatement) (Hammack et al, 2003; Henry et al, 2006; Land et al, 2008; Wang et al, 2007). CRF R2 mRNA expression was increased in 5-HT neurons of WKY rats. Unlike the CRF R1 responses, CRF R2-mediated augmentation of $\mathrm{GABA}_{\mathrm{A}}$-mediated currents was retained in WKY rats. In WKY rats, activation of CRF R2 still increased mIPSC amplitude (Kirby et al, 2008). In contrast, the CRF R2-mediated increase in inward current was absent. Thus, the net effect of CRF R2 activation on 5-HT neurons was exclusively inhibitory in the maladaptive stress state. However, this is counterbalanced by the emergent disinhibition caused by R2 responses on non-5-HT neurons.

In non-5-HT cells of WKY rats, CRF enhanced mIPSC frequency and amplitude. Although these neurons were not neurochemically identified, it is likely that these non-5-HT cells are GABAergic interneurons. The CRF R2 agonist Ucn II elicited responses in non-5-HT neurons; responses not normally seen in the neurons recorded from SD rats. Ucn II administration increased mIPSC amplitude in non-5-HT neurons of WKY rats. The CRF increase in mIPSC frequency and amplitude in concert with the Ucn II increase in 
amplitude in non-5-HT neurons in WKY rats would result in a reduction in the inhibitory tone on 5-HT neurons.

All of these changes in CRF effects seen in the WKY rat lead to a net disinhibition of the 5-HT neuron, that is, attenuation of CRF R1 responses in 5-HT neurons, retention of CRF R2-mediated increase in mIPSC amplitude, increase in mIPSC frequency, and amplitude in non-5-HT neurons. It has been shown that following exposure to acute swim stress, there is an increase in 5-HT turnover in limbic regions of WKY rats compared with Wistar rats, suggesting an increase in 5-HT release during stress in WKY rats. This study would be congruent with a shift in the modulatory effect of CRF from inhibitory to excitatory (De La Garza and Mahoney, 2004). In the context of behavioral inhibition, these data indicate that during a stress event when the DRN is activated, increased CRF would lead to an increase in 5 -HT levels in the forebrain, which in turn would heighten behavioral inhibition. This is consistent with the behavioral data indicating that WKY rats are more likely to adopt passive coping strategies more quickly when exposed to a stressor (Rittenhouse et al, 2002). In the future, dual recordings between GABA neurons and 5-HT neurons would be needed to confirm these effects and this proposed circuitry within the DRN.

Part of the mechanism underlying the changes in CRF responses in WKY rats may be because of a re-organization of the CRF $\mathrm{R} 1$ and $\mathrm{R} 2$ receptors on the plasma membrane. Recent evidence demonstrates that in control unstressed rats the CRF R1 in the DRN is on the plasma membrane and the CRF R2 receptors are primarily cytoplasmic. Swim stress reverses this distribution so that CRF R2 is on the plasma membrane and CRF R1 is internalized (Waselus et al, 2009). The net actions of $\mathrm{CRF}$ release shifted from primarily inhibitory to excitatory, as seen by an increase in firing rate.

In the stress-hyperresponsive WKY rats, this mechanism does not function normally, partially because of a dysregulated CRF system that may be the result of the heightened internal stress state of the animal and increased levels of CRF. The CRF $\mathrm{R} 1$ receptors are probably internalized with CRF R2 receptors predominating on the surface membrane. The data reported in this paper indicate that in stress-hyperresponsive WKY rats, CRF-mediated inhibition of 5-HT-containing cells of the DRN through augmentation of GABAergic synaptic activity is absent. Furthermore, this alteration in CRF modulation in WKY rats is specific to the DRN and not seen in the MRN despite evidence of CRF-mediated effects in the MRN. Finally, there was not a general overall attenuation in all of the CRF receptor-mediated responses; all of the responses mediated by CRF R1 were attenuated, but some of the responses mediated by CRF R2 were retained in the WKY rats.

\section{EtOH Has Similar GABAmimetic Effects in SD and WKY Rats}

WKY rats demonstrate an increased alcohol preference (Pare et al, 1999). The stress-hyperresponsivity characteristic of these rats may be responsible for potentiated alcohol preference. Alternatively, there may be a difference in efficacy of EtOH to exert its cellular effects, causing WKY rats to intake more alcohol to reach the same hedonic state. A plausible hypothesis was that EtOH has decreased efficacy in many regions of the WKY rat brain, but this was not the case in the DRN. At a midrange concentration, EtOH had similar GABAmimetic effects on mIPSC frequency and amplitude in 5-HT DRN neurons of SD and WKY rats. Therefore, in both these strains, EtOH robustly increased the inhibitory tone in the DRN, and therefore would subsequently decrease DRN discharge rates, thereby reducing the levels of 5-HT in forebrain. Future studies using a range of concentrations of EtOH may reveal differences in responsivity between SD and WKY. Work by Nie et al (2004) demonstrated that postsynaptic effects of EtOH (at a similar concentration used in this study) on GABAergic IPSCs can be blocked by pretreatment with a CRF R1 antagonist and was not apparent in CRF R1 KO mice. Similar to this study, we found that pretreatment with antalarmin was sufficient to attenuate the postsynaptic effect on mIPSC amplitude. However, the presynaptic increase in frequency following $\mathrm{EtOH}$ administration was not significantly attenuated by antalarmin, suggesting a separate mechanism for pre- and post-synaptic effects of EtOH. This finding is consistent with Nie et al (2004) and, moreover, demonstrates that this interaction with EtOH and CRF R1 is present in multiple regions. What remains elusive is the actual mechanism by which this interaction is occurring. Future studies must address how CRF R1 acts to influence the acute effects of $\mathrm{EtOH}$, and what possible implications this may have for understanding the interaction between stress and addiction.

\section{Final Conclusions}

There have been very few studies examining the electrophysiological changes that occur in a model of chronic stress or the stress-hyperresponsive WKY rat. The findings of this study suggest that basally, 5-HT neurons have lower excitability and TPH 2 production in WKY rats, and thus it is likely that these rats have basally lower levels of 5-HT. Although basal GABAergic signaling is normal in WKY rats compared with control animals, the modulation of GABAergic synaptic activity by clinically used allosteric modulators as well as by CRF is altered in these animals. The data presented in this paper demonstrate that CRF dysregulation may be a hallmark of chronic stress and depression in a highly region-specific manner. Clinically, CRF receptor antagonists have been pursued as possible antianxiety and antidepressant treatments. However, perhaps targeting CRF receptors globally is less efficacious than targeting specific regions of interest that are more critically involved in the pathology. This paper provides further evidence that CRF modulation of the 5-HT-containing nuclei is disrupted in a model of chronic stress and depression.

\section{ACKNOWLEDGEMENTS}

We thank Dr Jean Rivier of the Clayton Foundation Laboratories for Peptide Biology at The Salk Institute for his generous donations of oCRF and Ucn II for use in these studies. We also thank Abigail Schindler for her useful suggestions on the manuscript. This work was supported by grants from a Young Investigator Award from the National Alliance for Research on Schizophrenia and Depression 
(NARSAD) and the National Institute of Mental Health (MH 63301 and DA 20126) to LGK and NIMH (MH 60773) and the Office of Naval Research (N00014-03-1-0311) grants issued to Dr Beck.

\section{DISCLOSURE}

The authors declare no conflict of interest.

\section{REFERENCES}

Abumaria N, Ribic A, Anacker C, Fuchs E, Flugge G (2008). Stress upregulates TPH1 but not TPH2 mRNA in the rat dorsal raphe nucleus: identification of two TPH2 mRNA splice variants. Cell Mol Neurobiol 28: 331-342.

Adell A, Casanovas JM, Artigas F (1997). Comparative study in the rat of the actions of different types of stress on the release of 5HT in raphe nuclei and forebrain areas. Neuropharmacology 36: 735-741.

Beck SG, Pan YZ, Akanwa AC, Kirby LG (2004). Median and dorsal raphe neurons are not electrophysiologically identical. J Neurophysiol 91: 994-1005.

Clark MS, McDevitt RA, Hoplight BJ, Neumaier JF (2007). Chronic low dose ovine corticotropin releasing factor or urocortin II into the rostral dorsal raphe alters exploratory behavior and serotonergic gene expression in specific subregions of the dorsal raphe. Neuroscience 146: 1888-1905.

Conti LH, Youngblood KL, Printz MP, Foote SL (1997). Locus coeruleus electrophysiological activity and responsivity to corticotropin-releasing factor in inbred hypertensive and normotensive rats. Brain Res 774: 27-34.

Coppen AJ, Doogan DP (1988). Serotonin and its place in the pathogenesis of depression. J Clin Psychiatry 49(Suppl): 4-11.

Crawford LK, Craige CP, Beck SG (2010). Increased intrinsic excitability of lateral wing serotonin neurons of the dorsal raphe: a mechanism for selective activation in stress circuits. J Neurophysiol 103: 2652-2663.

Day HE, Greenwood BN, Hammack SE, Watkins LR, Fleshner M, Maier SF et al (2004). Differential expression of 5HT-1A, alpha $1 \mathrm{~b}$ adrenergic, CRF-R1, and CRF-R2 receptor mRNA in serotonergic, gamma-aminobutyric acidergic, and catecholaminergic cells of the rat dorsal raphe nucleus. J Comp Neurol 474: 364-378.

Deakin JF (1991). Depression and 5HT. Int Clin Psychopharmacol 6(Suppl 3): 23-28.

Drake CL, Roehrs T, Roth T (2003). Insomnia causes, consequences, and therapeutics: an overview. Depress Anxiety 18: 163-176.

De La Garza R, Mahoney III JJ (2004). A distinct neurochemical profile in WKY rats at baseline and in response to acute stress: implications for animal models of anxiety and depression. Brain Res 1021: 209-218.

Dilts RP, Boadle-Biber MC (1995). Differential activation of the 5-hydroxytryptamine-containing neurons of the midbrain raphe of the rat in response to randomly presented inescapable sound. Neurosci Lett 199: 78-80.

Gervasoni D, Peyron C, Rampon C, Barbagli B, Chouvet G, Urbain $\mathrm{N}$ et al (2000). Role and origin of the GABAergic innervation of dorsal raphe serotonergic neurons. J Neurosci 20: 4217-4225.

Gizatullin R, Zaboli G, Jonsson EG, Asberg M, Leopardi R (2008). The tryptophan hydroxylase (TPH) 2 gene unlike TPH-1 exhibits no association with stress-induced depression. J Affect Disord 107: $175-179$

Graeff FG, Guimaraes FS, De Andrade TG, Deakin JF (1996). Role of 5-HT in stress, anxiety, and depression. Pharmacol Biochem Behav 54: 129-141.
Grahame-Smith DG (1989). Serotonin function in affective disorders. Acta Psychiatr Scand 350(Suppl): 7-12.

Haddjeri N, Lucas G, Blier P (2000). Role of cholinergic and GABAergic systems in the feedback inhibition of dorsal raphe 5-HT neurons. NeuroReport 11: 3397-3401.

Hammack SE, Schmid MJ, LoPresti ML, Der-Avakian A, Pellymounter MA, Foster AC et al (2003). Corticotropin releasing hormone type 2 receptors in the dorsal raphe nucleus mediate the behavioral consequences of uncontrollable stress. J Neurosci 23: $1019-1025$.

Henry B, Vale W, Markou A (2006). The effect of lateral septum corticotropin-releasing factor receptor 2 activation on anxiety is modulated by stress. J Neurosci 26: 9142-9152.

Homanics GE, DeLorey TM, Firestone LL, Quinlan JJ, Handforth A, Harrison NL et al (1997). Mice devoid of gammaaminobutyrate type A receptor beta3 subunit have epilepsy, cleft palate, and hypersensitive behavior. Proc Natl Acad Sci USA 94: 4143-4148.

Kinney GG, Vogel GW, Feng P (1997). Decreased dorsal raphe nucleus neuronal activity in adult chloral hydrate anesthetized rats following neonatal clomipramine treatment: implications for endogenous depression. Brain Res 756: 68-75.

Kirby LG, Freeman-Daniels E, Lemos JC, Nunan JD, Lamy C, Akanwa A et al (2008). Corticotropin-releasing factor increases GABA synaptic activity and induces inward current in 5-hydroxytryptamine dorsal raphe neurons. I Neurosci 28: 12927-12937.

Kirby LG, Pan YZ, Freeman-Daniels E, Rani S, Nunan JD, Akanwa A et al (2007). Cellular effects of swim stress in the dorsal raphe nucleus. Psychoneuroendocrinology 32: 712-723.

Kirby LG, Rice KC, Valentino RJ (2000). Effects of corticotropinreleasing factor on neuronal activity in the serotonergic dorsal raphe nucleus. Neuropharmacology 22: 148-162.

Korpi ER, Sinkkonen ST (2006). GABA(A) receptor subtypes as targets for neuropsychiatric drug development. Pharmacol Ther 109: $12-32$.

Lahmame A, del Arco C, Pazos A, Yritia M, Armario A (1997). Are Wistar-Kyoto rats a genetic animal model of depression resistant to antidepressants? Eur J Pharmacol 337: 115-123.

Land BB, Bruchas MR, Lemos JC, Xu M, Melief EJ, Chavkin C (2008). The dysphoric component of stress is encoded by activation of the dynorphin kappa-opioid system. J Neurosci 28 : 407-414.

Lemos JC, Pan YZ, Ma X, Lamy C, Akanwa AC, Beck SG (2006). Selective 5-HT receptor inhibition of glutamatergic and GABAergic synaptic activity in the rat dorsal and median raphe. Eur J Neurosci 24: 3415-3430.

Leonard BE (2005). The HPA and immune axes in stress: the involvement of the serotonergic system. Eur Psychiatry 20(Suppl 3): S302-S306.

Lopez-Rubalcava C, Lucki I (2000). Strain differences in the behavioral effects of antidepressant drugs in the rat forced swimming test. Neuropsychopharmacology 22: 191-199.

Lovenberg TW, Liaw CW, Grigoriadis DE, Clevenger W, Chalmers DT, De Souza EB et al (1995). Cloning and characterization of a functionally distinct corticotropin-releasing factor receptor subtype from rat brain. Proc Natl Acad Sci USA 92: 836-840.

Lowry CA, Hale MW, Evans AK, Heerkens J, Staub DR, Gasser PJ et al (2008). Serotonergic systems, anxiety, and affective disorder: focus on the dorsomedial part of the dorsal raphe nucleus. Ann NY Acad Sci 1148: 86-94.

Lukkes JL, Forster GL, Renner KJ, Summers CH (2008). Corticotropin-releasing factor 1 and 2 receptors in the dorsal raphe differentially affect serotonin release in the nucleus accumbens. Eur J Pharmacol 578: 185-193.

Maier SF, Watkins LR (2005). Stressor controllability and learned helplessness: the roles of the dorsal raphe nucleus, serotonin, and corticotropin-releasing factor. Neurosci Biobehav Rev 29: 829-841. 
McEuen JG, Beck SG, Bale TL (2008). Failure to mount adaptive responses to stress results in dysregulation and cell death in the midbrain raphe. J Neurosci 28: 8169-8177.

Mohler H (2006). GABA(A) receptor diversity and pharmacology. Cell Tissue Res 326: 505-516.

Moss SJ, Smart TG (2001). Constructing inhibitory synapses. Nat Rev Neurosci 2: 240-250.

Nie Z, Schweitzer P, Roberts AJ, Madamba SG, Moore SD, Siggins GR (2004). Ethanol augments GABAergic transmission in the central amygdala via CRF1 receptors. Science 303: 1512-1514.

Nishikawa T, Scatton B (1983). Evidence for a GABAergic inhibitory influence on serotonergic neurons originating from the dorsal raphe. Brain Res 279: 325-329.

Nishikawa T, Scatton B (1984). The inhibitory GABAergic influence on striatal serotonergic neurons depends upon the habenulo-raphe pathways. Brain Res 304: 157-161.

Nishikawa T, Scatton B (1985). Inhibitory influence of GABA on central serotonergic transmission. Raphe nuclei as the neuroanatomical site of the GABAergic inhibition of cerebral serotonergic neurons. Brain Res 331: 91-103.

Pare AM, Pare WP, Kluczynski J (1999). Negative affect and voluntary alcohol consumption in Wistar-Kyoto (WKY) and Sprague-Dawley rats. Physiol Behav 67: 219-225.

Pare WP (1989a). 'Behavioral despair' test predicts stress ulcer in WKY rats. Physiol Behav 46: 483-487.

Pare WP (1989b). Stress ulcer susceptibility and depression in Wistar Kyoto (WKY) rats. Physiol Behav 46: 993-998.

Pare WP (1993). Passive-avoidance behavior in Wistar-Kyoto (WKY), Wistar, and Fischer-344 rats. Physiol Behav 54: 845-852.

Pare WP (1994a). Hyponeophagia in Wistar Kyoto (WKY) rats. Physiol Behav 55: 975-978.

Pare WP (1994b). Open field, learned helplessness, conditioned defensive burying, and forced-swim tests in WKY rats. Physiol Behav 55: 433-439.

Pare WP (2000). Investigatory behavior of a novel conspecific by Wistar Kyoto, Wistar and Sprague-Dawley rats. Brain Res Bull 53: 759-765.

Pare WP, Redei E (1993a). Depressive behavior and stress ulcer in Wistar Kyoto rats. J Physiol Paris 87: 229-238.

Pare WP, Redei E (1993b). Sex differences and stress response of WKY rats. Physiol Behav 54: 1179-1185.

Pare WP, Tejani-Butt SM (1996). Effect of stress on the behavior and 5-HT system in Sprague-Dawley and Wistar Kyoto rat strains. Integr Physiol Behav Sci 31: 112-121.

Pearson KA, Stephen A, Beck SG, Valentino RJ (2006). Identifying genes in monoamine nuclei that may determine stress vulnerability and depressive behavior in Wistar-Kyoto rats. Neuropsychopharmacology 31: 2449-2469.

Penington NJ, Kelly JP, Fox AP (1993). Whole-cell recordings of inwardly rectifying $\mathrm{K}^{+}$currents activated by $5-\mathrm{HT}_{1 \mathrm{~A}}$ receptors on dorsal raphe neurones of the adult rat. J Physiol 469: 387-405.

Pistis M, Muntoni AL, Gessa G, Diana M (1997). Effects of acute, chronic ethanol and withdrawal on dorsal raphe neurons: electrophysiological studies. Neuroscience 79: 171-176.

Pollier F, Sarre S, Aguerre S, Ebinger G, Mormede P, Michotte Y et al (2000). Serotonin reuptake inhibition by citalopram in rat strains differing for their emotionality. Neuropsychopharmacology 22: 64-76.

Price ML, Curtis AL, Kirby LG, Valentino RJ, Lucki I (1998). Effects of corticotropin-releasing factor on brain serotonergic activity. Neuropharmacology 18: 492-502.

Price ML, Kirby LG, Valentino RJ, Lucki I (2002). Evidence for corticotropin-releasing factor regulation of serotonin in the lateral septum during acute swim stress: adaptation produced by repeated swimming. Psychopharmacology (Berl) 162 406-414.

Price ML, Lucki I (2001). Regulation of serotonin release in the lateral septum and striatum by corticotropin-releasing factor. J Neurosci 21: 2833-2841.

Ramadan E, Fu Z, Losi G, Homanics GE, Neale JH, Vicini S (2003). GABA(A) receptor beta3 subunit deletion decreases alpha2/3 subunits and IPSC duration. J Neurophysiol 89: 128-134.

Richardson-Jones JW, Craige CP, Guiard BP, Stephen A, Metzger KL, Kung HF et al (2010). 5-HT1A autoreceptor levels determine vulnerability to stress and response to antidepressants. Neuron 65: 40-52.

Rittenhouse PA, Lopez-Rubalcava C, Stanwood GD, Lucki I (2002). Amplified behavioral and endocrine responses to forced swim stress in the Wistar-Kyoto rat. Psychoneuroendocrinology 27: 303-318.

Robinson DS, Alms DR, Shrotriya RC, Messina M, Wickramaratne P (1989). Serotonergic anxiolytics and treatment of depression. Psychopathology 22(Suppl 1): 27-36.

Roche M, Commons KG, Peoples A, Valentino RJ (2003). Circuitry underlying regulation of the serotonergic system by swim stress. J Neurosci 23: 970-977.

Ruhe HG, Mason NS, Schene AH (2007). Mood is indirectly related to serotonin, norepinephrine and dopamine levels in humans: a meta-analysis of monoamine depletion studies. Mol Psychiatry 12: 331-359.

Schmidt MV, Sterlemann V, Muller MB (2008). Chronic stress and individual vulnerability. Ann NY Acad Sci 1148: 174-183.

Scholl JL, Renner KJ, Forster GL, Tejani-Butt S (2010). Central monoamine levels differ between rat strains used in studies of depressive behavior. Brain Res 1355: 41-51.

Shishkina GT, Kalinina TS, Dygalo NN (2008). Serotonergic changes produced by repeated exposure to forced swimming: correlation with behavior. Ann NY Acad Sci 1148: 148-153.

Stockmeier CA (1997). Neurobiology of serotonin in depression and suicide. Ann NY Acad Sci 836: 220-232.

Tao R, Auerbach SB (2002). GABAergic and glutamatergic afferents in the dorsal raphe nucleus mediate morphine-induced increases in serotonin efflux in the rat central nervous system. J Pharmacol Exp Ther 303: 704-710.

Tejani-Butt S, Kluczynski J, Pare WP (2003). Strain-dependent modification of behavior following antidepressant treatment. Prog Neuropsychopharmacol Biol Psychiatry 27: 7-14.

Tejani-Butt SM, Pare WP, Yang J (1994). Effect of repeated novel stressors on depressive behavior and brain norepinephrine receptor system in Sprague-Dawley and Wistar Kyoto (WKY) rats. Brain Res 649: 27-35.

Walker E, Mittal V, Tessner K (2008). Stress and the hypothalamic pituitary adrenal axis in the developmental course of schizophrenia. Annu Rev Clin Psychol 4: 189-216.

Wang B, You ZB, Rice KC, Wise RA (2007). Stress-induced relapse to cocaine seeking: roles for the $\mathrm{CRF}(2)$ receptor and $\mathrm{CRF}$ binding protein in the ventral tegmental area of the rat. Psychopharmacology (Berl) 193: 283-294.

Waselus M, Nazzaro C, Valentino RJ, Van Bockstaele EJ (2009). Stress-induced redistribution of corticotropin-releasing factor receptor subtypes in the dorsal raphe nucleus. Biol Psychiatry 66: 76-83.

Will CC, Aird F, Redei EE (2003). Selectively bred Wistar-Kyoto rats: an animal model of depression and hyper-responsiveness to antidepressants. Mol Psychiatry 8: 925-932.

Zafar HM, Pare WP, Tejani-Butt SM (1997). Effect of acute or repeated stress on behavior and brain norepinephrine system in Wistar-Kyoto (WKY) rats. Brain Res Bull 44: 289-295. 